\title{
Treatment efficacy of a specialized psychotherapy program for Internet Gaming Disorder
}

\author{
ALEXANDRA TORRES-RODRÍGUEZ ${ }^{1 *}$, MARK D. GRIFFITHS ${ }^{2}$, XAVIER CARBONELL $^{1}$ and URSULA OBERST ${ }^{1}$ \\ ${ }^{1}$ Psychology Department, FPCEE Blanquerna, Universitat Ramon Llull, Barcelona, Spain \\ ${ }^{2}$ International Gaming Research Unit, Psychology Department, Nottingham Trent University, Nottingham, UK
}

(Received: May 10, 2018; revised manuscript received: July 26, 2018; second revised manuscript received: October 10, 2018; accepted: October 14, 2018)

\begin{abstract}
Background and aims: Internet Gaming Disorder (IGD) has become health concern around the world, and specialized health services for the treatment of IGD are emerging. Despite the increase in such services, few studies have examined the efficacy of psychological treatments for IGD. The primary aim of this study was to assess the efficacy of a specialized psychotherapy program for adolescents with IGD [i.e., the "Programa Individualizado Psicoterapéutico para la Adicción a las Tecnologías de la Información y la Comunicación” (PIPATIC) program]. Methods: The sample comprised 31 adolescents (aged 12-18 years) from two public mental health centers who were assigned to either the (a) PIPATIC intervention experimental group or (b) standard cognitive-behavioral therapy (CBT) control group. The interventions were assessed at pre-, middle-, and post-treatment phases, as well as a 3-month assessment was carried out after completing the interventions. Results: No significant differences between either group in the pre-treatment phase were found. Relating to the different interventions examined, significant differences were found at pre-test and post-test on the following variables: comorbid disorders, intrapersonal and interpersonal abilities, family relationships, and therapists' measures. Both groups experienced a significant reduction of IGD symptoms, although the PIPATIC group experienced higher significant improvements in the remainder of the variables examined. Discussion and conclusions: The findings suggest that PIPATIC program is effective in the treatment of IGD and its comorbid disorders/symptoms, alongside the improvement of intra- and interpersonal abilities and family relationships. However, it should also be noted that standard CBT was also effective in the treatment of IGD. Changing the focus of treatment and applying an integrative focus (including the addiction, the comorbid symptoms, intra- and interpersonal abilities, and family psychotherapy) appear to be more effective in facilitating adolescent behavior change than CBT focusing only on the IGD itself.
\end{abstract}

Keywords: Internet Gaming Disorder, adolescence, video game, gaming disorder treatment, cognitive-behavioral therapy

\section{INTRODUCTION}

The excessive and problematic use of technology has led to increasing public health concerns around the world (World Health Organization, 2016). Consequently, specialized health services have emerged with outpatient treatment for various technological addictions (Martín-Fernández, Matalí, García-Sánchez, Pardo, \& Castellano-Tejedor, 2016; Young, 2007). There has also been recognition that excessive maladaptive use of online video games can lead to associated psychological problems for a small minority of individuals, particularly adolescents (e.g., Ferguson, Coulson, \& Barnett, 2011; Kuss \& Griffiths, 2012). This has led to the introduction of treatment services for problems related to video game playing among adolescents as a consequence of the risks and vulnerabilities related to this life stage (e.g., Kuss \& Griffiths, 2012; Schneider, King, \& Delfabbro, 2017; Torres-Rodríguez \& Carbonell, 2017).
Although the study of Internet Gaming Disorder (IGD) has grown markedly in recent years, few studies have examined the efficacy of psychological treatments and pharmacological interventions for IGD (Griffiths, 2008; King, Delfabbro, Griffiths, \& Gradisar, 2011; King et al., 2017). Most of the studies, to date, have been carried out in Asian countries where the prevalence of IGD appears to be higher than other areas of the world (Du, Jiang, \& Vance, 2010; Kim, 2008; King et al., 2017). Furthermore, systematic reviews related to IGD treatments have expanded the nomenclature to include internet addiction, since this term is commonly used by Asian countries where most of the treatment studies carried out (King et al., 2017; Winkler, Dörsing, Rief, Shen, \& Glombiewski, 2013). However, very

* Corresponding author: Alexandra Torres-Rodríguez; Psychology Department, FPCEE Blanquerna, Universitat Ramon Llull, 34 Císter Street, Barcelona 08022, Spain; Phone: +34 9325330 00; Fax: +34 9325330 32; E-mail: alexandrart@blanquerna.url.edu

This is an open-access article distributed under the terms of the Creative Commons Attribution-NonCommercial 4.0 International License, which permits unrestricted use, distribution, and reproduction in any medium for non-commercial purposes, provided the original author and source are credited, a link to the CC License is provided, and changes - if any - are indicated. 
few treatment programs have been developed in the USA or European countries (King et al., 2017; Thorens et al., 2014; Wölfling, Beutel, Dreier, \& Muller, 2014; Young, 2007, 2013). Furthermore, there has been little evaluation concerning the effects of different psychological interventions with children and adolescents (King, Delfabbro, \& Griffiths, 2013; King \& Delfabbro, 2017). Consequently, there is an evident need to develop and evaluate IGD treatments for European youth.

Based on the peer-reviewed literature, cognitive-behavior therapy (CBT) appears to be the most commonly applied treatment for online addictions including IGD (Greenfield, 1999; Griffiths \& Meredith, 2009; Kaptsis, King, Delfabbro, \& Gradisar, 2016; King, Delfabbro, \& Griffiths, 2010; King et al., 2011; Young, 2007, 2013). Along these lines, most of the therapeutic recommendations of CBTs for online addictions, such as IGD, are based on substance abuse treatment (Huang, Li, \& Tao, 2010; King et al., 2011), including stimulus control, learning appropriate coping responses, self-monitoring strategies, cognitive restructuring, problem solving related to addiction, and withdrawal regulation techniques with exposure (Griffiths \& Meredith, 2009; King et al., 2010; Young, 2007). Previous studies have suggested an integrative approach for specialized treatments of IGD due to the high presence of comorbid disorders and associated problems, as well as interventions that address low self-esteem, poor social skills, low emotional intelligence, and family dysfunction (among others) in order to address the disorder more holistically. In particular, previous IGD studies have reported psychological problems including affective instability, low self-esteem, insecure personality, shyness, loneliness, limited leisure activities, family deficits, maladaptive coping styles, lower social competence, and lower school performance (e.g., Gentile et al., 2011; Kim, Namkoong, Ku, \& Kim, 2008; King \& Delfabbro, 2017; Kuss, van Rooij, Shorter, Griffiths, \& van de Mheen, 2013; Lemmens, Valkenburg, \& Peter, 2011; Liebert, Lo, Ph, Wang, \& Fang, 2005; Rehbein, Psych, Kleimann, Mediasci, \& Mößle, 2010; Schneider et al., 2017; Tejeiro, Gómez-Vallecillo, Pelegrina, Wallace, \& Emberley, 2012). Other disorders associated with symptoms of IGD include anxiety disorders, depression, suicidal ideation, behavioral disorders, social phobia, autism spectrum disorder, attention-deficit hyperactivity disorder, obsessive-compulsive disorder, and personality disorders (e.g., Andreassen et al., 2016; Chan \& Rabinowitz, 2006; Ferguson et al., 2011; Gentile et al., 2011; Han, Lee, Shi, \& Renshaw, 2014; Kelleci \& Inal, 2010; Kim et al., 2006; Ko et al., 2006; Shapira, Goldsmith, Keck, Khosla, \& McElroy, 2000).

A recent systematic review of 30 IGD treatment studies (King et al., 2017) suggested that CBT treatment had a large empirical base compared to other interventions. Nevertheless, the review reported a number of limitations regarding the studies evaluated. More specifically, (a) one-third of the studies did not employ control groups, (b) there was a lack of sample size justification and information about recruitment and intervention, (c) there were inconsistencies in assessment of treatment outcomes and a lack of follow-up in several studies, (d) most of the psychological interventions focused on CBT programs often lacking detail in the descriptions of the treatments, (e) many studies employed different diagnostic tool, (f) the randomization and presence of control groups were scarce, and (g) many studies focused on the assessment of gaming symptoms leaving aside the diagnostic changes and/or the comorbid symptoms. The few published studies present many limitations (King et al., 2017) and comprise many challenges that hinder the rigorous application of CONSORT guidelines guaranteeing the quality of clinical trials (Schulz, Altman, \& Moher, 2010).

Consequently, there is an evident need to develop and evaluate comprehensive and specialized treatments for IGD among European children and adolescents. This study contributes to such scientific need by evaluating a comprehensive and specialized IGD treatment program applied to a western youth population. This study also compared the treatment efficacy of two psychological treatments among a sample of treatment-seeking adolescents: a specialized psychotherapy program for adolescents with IGD (i.e., the PIPATIC program: "Programa Individualizado Psicoterapéutico para la Adicción a las Tecnologías de la Información y la Comunicación") and standard CBT. It was expected that PIPATIC program would lead to improvement in both psychotherapeutically focused areas and reduced symptoms of IGD, whereas the CBT program would only lead to reduction in IGD symptoms. The study provides useful empirical and clinical data about the effects and efficacy of a newly developed IGD treatment program and attempts to overcome some of the limitations in previously reported IGD treatment studies. Compared to previous reports of IGD treatment, this study included: (a) a detailed description of the treatment program (outlined in previous papers by the present authors; see Torres-Rodríguez \& Carbonell, 2017; Torres-Rodríguez, Griffiths, \& Carbonell, 2017); (b) a clinical sample of European adolescents; (c) an intervention control group (standard CBT); (d) comparison of symptoms across four different assessment points (pre-, middle-, posttreatment, and follow-up); (e) the use of clinical interviews, alongside validated and reliable instruments for use with participants, relatives, and therapists; and (f) assessments and evaluations by trained clinical psychologists comprising clinical interviews, administering of reliable psychometric instruments, and rigorous assessment of comorbid symptoms and problems associated with IGD.

The primary goal of the newly developed PIPATIC program (see Torres-Rodríguez et al., 2017 for an in-depth description) is to offer specialized psychotherapy for adolescents with symptoms of IGD and comorbid disorders. The program comprises six therapeutic work modules, in turn made up of more specific subobjectives. Following previous studies (Hansen \& Lambert, 2003; Kadera, Lambert, \& Andrews, 1996; Lambert \& Bergin, 1994) - and in order to ensure therapeutic changes in patients - the duration of the program was 6 months (22 sessions of approximately 45-min duration). The intervention, based on a CBT approach, employed crosscutting techniques and resources commonly used in psychotherapy (Hofmann \& Barlow, 2014; Kleinke, 1994; Laska, Gurman, \& Wampold, 2014). The design of the PIPATIC program integrates several areas of intervention structured into six modules: (a) psychoeducation and motivation, (b) addiction treatment as usual (TAU) adapted to IGD, (c) intrapersonal, (d) interpersonal, (e) family intervention, and (f) development of new lifestyle. 


\section{METHODS}

\section{Participants}

The sample originally comprised 58 adolescents who voluntarily sought treatment for their problematic video game playing in two public mental health centers in the Barcelona metropolitan area (Spain) during the 18-month period when the study was carried out. Of these, 12 participants were considered as lost (because they did not return to the treatment center after a first visit) and 12 more participants were excluded for not meeting the inclusion criteria of this study (i.e., four participants did not meet the inclusion criteria (a) and (b) below; one was under 12 years; two participants presented with a severe mental disorder where the primary disorder needed treating as opposed to the IGD; and five participants declined to participate in the study). Of these treatment-seekers, 34 met the inclusion criteria and 31 participants (aged 12-18 years) completed the treatment and completed follow-up measures (Figure 1). One participant dropped out the PIPATIC treatment and two participants dropped out the standard treatment. Participants did not report any other current psychotherapy treatment. The inclusion criteria were: (a) endorsing at least five or more of the nine IGD criteria according to DSM-5 (American Psychiatric Association [APA], 2013); (b) scoring 71 or more on Internet Gaming Disorder Test (IGD-20 Test; Pontes, Király, Demetrovics, \& Griffiths, 2014) adapted to Spanish population (Fuster, Carbonell, Pontes, \& Griffiths, 2016); (c) being aged 12-18 years; (d) not having a severe mental disorder (i.e., schizophrenia, schizoaffective disorder, and bipolar disorder) or intellectual disability; and (e) understanding the Spanish language. Thus, the final sample comprised 31 male adolescents diagnosed with IGD.

\section{Measures}

Video game habits and IGD

Weekly hours spent gaming: This measure was obtained through self-reports from the participants and their relatives by asking about the approximate number of hours that were spent gaming during weekdays and the weekend (holiday periods were excluded).

Ability to stop gaming: Participants and their families self-reported the ability to stop gaming using a simple Likert scale (1-5). More specifically, they were asked how difficult it was to stop gaming to do more important activities where 1 was "never having difficulties to stop their gaming" and 5 was "always having problems to stop gaming."

Self-awareness of engagement in gaming: Participants and their families were asked to what extent they were engaged in gaming using a simple Likert scale (1-10), where 10 was the maximum engagement (i.e., totally addicted to gaming).

Internet Gaming Disorder Test (IGD-20 Test; Pontes et al., 2014): To assess IGD, the validated Spanish version of 20-item IGD Test was used (Fuster et al., 2016). The scale comprises six dimensions: salience (e.g., "I often lose sleep because of long gaming sessions"), mood modification (e.g., "I never play games in order to feel better"), tolerance (e.g., "I have significantly increased the amount of time I play games over last year"), withdrawal symptoms (e.g., "When I am not gaming I feel more irritable"), conflict (e.g., "I have lost interest in other hobbies because of my gaming"), and relapse (e.g., "I would like to cut down my gaming time but it is difficult to do"). All items are answered using a simple Likert scale (1-5, "strongly disagree," "disagree," "neither agree," "agree," and "strongly agree"). The minimum and maximum scores are 20 and 100 , respectively, and those scoring 71 or more are classed as having IGD. Cronbach's $\alpha$ for the IDG-20 Test in this study was .87 .

Comorbid symptoms. Comorbid symptoms were assessed from both family and patient perspectives. To assess comorbid disorders as well as the behavioral and emotional functioning of the patients, the two scales from the Achenbach System of Empirically Based Assessment were used. These were the Youth Self-Report for Ages 11-18 Years (YSR/11-18) and the Child Behavior Checklist for Ages 6-18 Years (CBCL/6-18) in their Spanish validated

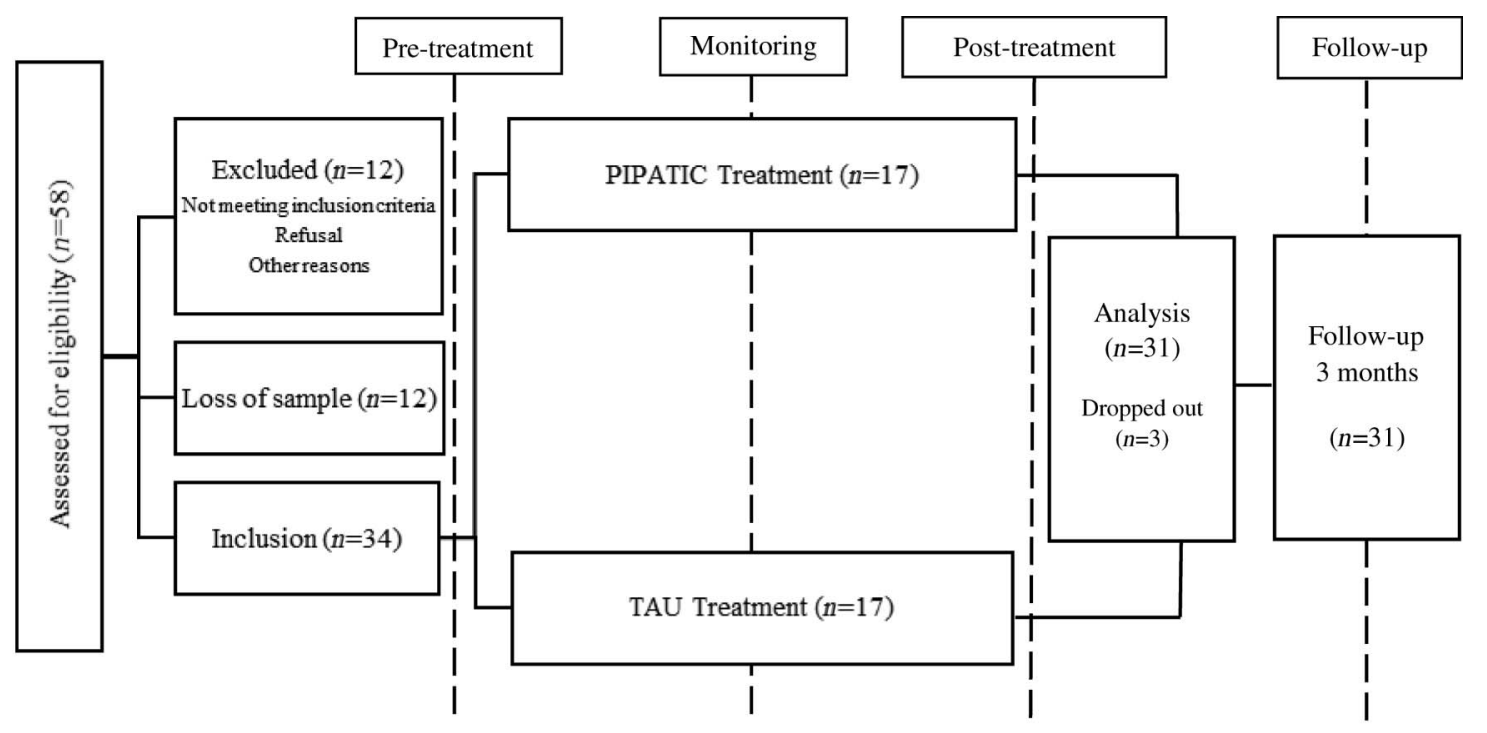

Figure 1. Schematic diagram of the recruitment and the methodological process 
versions (Achenbach \& Rescorla, 2001). The YSR/11-18 is a 112-item self-report scale completed by the adolescents, and the CBCL/6-18 is the version for their parents. The first part of both instruments assesses the psychosocial competencies of adolescents across four subscales (7 items; e.g., "Please list the sports you most like to take part in"), and the second part assesses behavioral and emotional symptoms across eight subscales (113 items; Table 5; e.g., "I argue a lot"). For the scoring, ADM v.910 School-Age Module for CBCL and YSR was used. Both scales have been validated for the Spanish population, and both obtaining high validity and internal consistency. For example, the internalizing and externalizing problem scales have been reported as having a Cronbach's $\alpha$ of .80 (Lemos, Fidalgo, Calvo, \& Menéndez, 1992).

Intrapersonal and interpersonal abilities. The Expressed Concern Scales of the Millon Adolescent Clinical Inventory (MACI; Millon, 1994) in its Spanish validated version were used to assess intrapersonal abilities. More specifically, (a) "identity diffusion" (e.g., "I often feel with no direction in mind"), (b) "self-devaluation" (e.g., "I don't like being the person I have become"), and (c) "body disapproval" (e.g., "I think I have a good body"). The MACI is a widely used validated and standardized instrument to assess adolescent personality patterns (12 subscales), expressed concerns ( 8 subscales), and clinical syndromes (7 subscales), in addition to four validity (modifying) scales. This study used the Spanish version of MACI and comprised 160 items. Possible answers were either "true" or "false." The standardized base rate (BR) scores were used in this study; BR scores of 0 and 115 were selected to represent the minimum and maximum possible on each scale. This study followed the scoring guidelines described in the Spanish manual (Millon, 2004). To assess the intrapersonal abilities, the Expressed Concern Scales were used. Cronbach's $\alpha$ reliabilities of MACI scales ranged from .73 to .91 .

The Trait Meta-Mood Scale (TMMS-24; Salovey, Mayer, Goldman, Turvey, \& Palfai, 1995) was used to assess intrapersonal abilities. The TMMS-24 is a 24-item instrument and uses a 5-point Likert scale to assess perceived emotional intelligence. The Spanish version of the TMMS-24 was used (Fernandez-Berrocal, Extremera, \& Ramos, 2004). The TMMS-24 is widely used in adolescents and adults, and comprises three subscales: (a) attention to emotion (participants' self-perception of the degree to which they pay attention to their own moods and emotions; e.g., "I pay much attention to my feelings"), (b) clarity (participants' self-perception of the degree to which they understand their own emotions; e.g., "I am usually very clear with my feelings"), and (c) repair of emotion (participants' selfperception of the degree to which they are able to modify their own emotions; e.g., "When I am upset, I think of all the pleasure of life"). The Spanish TMMS-24 has psychometric characteristics similar to the original version with an internal consistency (Cronbach's $\alpha$ ) of .90, .90, and .86 for attention, clarity, and repair, respectively. For this study, the benchmarks for males described in the Spanish version were used (Fernandez-Berrocal et al., 2004).

The Escala de Habilidades Sociales (EHS - Social Skills Scale; Gismero, 2000) is a 32-item Spanish scale used to assess the interpersonal abilities (e.g., "I sometimes avoid making questions because of my fear to appear stupid"). Scale items are assessed using a self-report 4-point Likert scale that can be completed by both adolescents and adults. This instrument has adequate validity and high internal consistency (with a Cronbach's $\alpha$ of .88). The young male scoring guidelines described in the manual were used for this study (Gismero, 2000).

Family relationships. To assess the impact of IGD treatment on the participant's family relationships, the Family Discord (G) scale (e.g., "I like my home") from the Spanish MACI test was used. This scale is part of the Expressed Concerns Scales of MACI test, and assesses the adolescent's personal perceptions regarding family conflicts.

Therapist measures. To assess clinical severity and change over time of each participant, the Spanish validated version of the Clinical Global Impression Scale - Severity of Illness (CGI-SI) was used (Busner \& Targum, 2007) (e.g., "Considering your total clinical experience with this particular population, how mentally ill is the patient at this time?'). The severity was assessed on a scale of $1-7$, with 1 being normal (shows no signs of illness) and 7 being the most extremely ill of patients. To assess the changes, the Clinical Global Impression Scale - Global Improvement (CGI-GI) was used (Busner \& Targum, 2007) (e.g., "Compared to your patient's condition at time of first assessment, how much has s/he changed?"), with 1 being very much improved and 7 being very much worse. To assess the global functioning activity, the Spanish version of the 1-item Global Assessment of Functioning (GAF) scale was used, extracted from DSM-IV-TR (APA, 2002). This one item considers the psychological, social, and occupational functioning on a hypothetical continuum of mental health illness [e.g., "Consider psychological, social and occupational functioning on a hypothetical continuum of mental health-illness. Do not include impairment in functioning due to physical (or environmental) limitations"] and comes with a description of what constitutes high and low scores. Scores range from 0 to 100 , with 0 being the persistent danger of severely hurting oneself or others and 100 being superior functioning in a wide range of activities. For instance, scores of 91-100 are described as being: "Superior functioning in a wide range of activities, life's problems never seem to get out of hand, is sought out by others because of his or her many positive qualities. No symptoms," whereas scores of 1-10 are described as being: "Persistent danger of severely hurting self or others (e.g., recurrent violence) $O R$ persistent inability to maintain minimal personal hygiene OR serious suicidal act with clear expectation of death."

Satisfaction with the treatment. The Working Alliance Theory of Change Inventory (WATOCI; Horvath \& Greenberg, 1989) is a 17-item scale answered by individuals and used to evaluate aspects, such as therapeutic alliance and patient satisfaction with the treatment (e.g., "I think that the things I do in therapy help me to get the changes that I want"). It has been validated for Spanish population (Corbella \& Botella, 2004) with a high internal consistency (with a Cronbach's $\alpha$ of .93). 


\section{Procedure}

Data acquisition. Before the treatment program was launched, a pilot study had been implemented to assess the operationalization of the intervention design and to identify any potential problems regarding the intervention (Torres-Rodríguez \& Carbonell, 2015). Following this, specialized training for health teams in the collaborating public mental health institutions was carried out to provide information about the study along with the inclusion/exclusion criteria, and to train individuals to carry out clinical interviews to assess IGD symptoms and other comorbid disorders. The training aim was to provide treatment strategies to the health teams (comprising psychiatrists, clinical psychologists, general practitioners, and nurses) to identify the problem in child and adolescent populations. Data collection comprised clinical interviews and data from the administration of diagnostic instruments. The clinical interviews were conducted by clinical psychologists, who also applied the diagnostic tests. The participants carried out repeated measurements during the treatment process: pre-treatment (T1), post-treatment (T3), and 3-month follow-up (T4). In addition, participants completed a brief measurement during the middle of the program (T2, 11th session) to assess the change process during the interventions. The parents of the participants were included in all of these stages and completed their own instruments [(a) weekly hours spent gaming, (b) perceived ability to stop gaming, (c) self-awareness of engagement in gaming, and (d) the CBCL/6-18]. The therapists also completed their own measures in each assessment (CGI-SI, CGIGI, and GAF). There was no significant data loss during this process. The trained psychologists tried to ensure the highest quality of data collection in each repeated measurement providing specific instructions to each participant and their relatives.

Interventions: Individualized psychotherapy treatment for IGD (PIPATIC program) and TAU. The primary goal of the PIPATIC (Torres-Rodríguez \& Carbonell, 2017; Torres-Rodríguez et al., 2017) was to offer specialized psychotherapy for adolescents with symptoms of IGD and comorbid disorders. This program comprises six therapeutic work modules, in turn made up of more specific subobjectives, in order to address different life areas and not just addictive behaviors (Table 1). Following previous studies (Hansen \& Lambert, 2003; Kadera et al., 1996; Lambert \& Bergin, 1994), in order to ensure therapeutic changes in patients, the scheduled duration of the program is 6 months (22 sessions of around 45-min weekly sessions). The intervention, based on a cognitive-behavioral approach, employs crosscutting techniques and resources common in psychotherapy (Hofmann \& Barlow, 2014; Kleinke, 1994; Laska et al., 2014). The design and content of PIPATIC has previously been described in detail (i.e., TorresRodríguez \& Carbonell, 2017; Torres-Rodríguez et al., 2017), providing the in-depth clinical and methodological aspects. The experimental group received the PIPATIC specialized treatment.

The control group also received psychological attention, because the use of the waiting list was considered unethical according to the following considerations: (a) the participants were minors and were in a stage of increased vulnerability, (b) the participants presented with a high level of psychological symptomatology and distress, and (c) it was necessary to attend to the needs and demands of the family. For that reason, it was decided to apply a standard CBT (or TAU) intervention for addiction. One of the most commonly adapted CBT approaches for gaming addiction was used (Greenfield, 1999; Griffiths \& Meredith, 2009; Kaptsis et al., 2016; King et al., 2010, 2017; Winkler et al., 2013; Young, 2007, 2013). The standard CBT intervention was extracted from the second module of PIPATIC (Table 1) (Torres-Rodríguez et al., 2017) and was applied to the control group across 22 sessions with greater depth of addiction psychotherapeutic work. This standard CBT treatment comprised five modules: (a) addiction stimulus control, (b) coping responses, (c) cognitive restructuring, (d) problem solving related to addiction, and (e) exposition (for more in-depth information regarding these modules, see Torres-Rodríguez et al., 2017). The level of families' participation in the standard CBT and in PIPATIC program intervention was different. In both interventions, the relatives acted as co-therapists in working with the gaming addiction. However, in the PIPATIC program, the relatives participated in a specific therapeutic module of family therapy. The relatives attended all sessions in both groups (i.e., in each specific module that required their involvement they completed the therapeutic tasks and recorded the adolescents' gaming). In the PIPATIC program, the relatives were involved in two sessions of the psychoeducational module, and in two sessions of standard CBT module. In the family module, they assisted in the totality of the sessions and were involved in the totality of the

Table 1. Summary of the psychotherapeutic modules of the PIPATIC program

1. Psychoeducational module: individual and family psychoeducation, motivational interviewing, choosing goals and objectives (three sessions)

2. Standard CBT addiction intervention module: stimulus control, learning appropriate coping responses, cognitive restructuration, problem solving related to addiction, exposure... (five sessions)

3. Intrapersonal module: psychotherapeutic work on identity, self-esteem, self-control, emotional-intelligence, and anxiety control (five sessions)

4. Interpersonal module: encouraging adaptive communication skills, assertiveness, and increasing communication skills (two sessions)

5. Familiar module: family communication, limits, and affect (three sessions)

6. Development of a new lifestyle module: self-observation of improvement, alternative activities, and relapse prevention (two sessions)

Note. The PIPATIC program includes two floating sessions that can be incorporated into the module that the therapist chooses, according to the needs of the patient. In this way, the set program offers some flexibility (Carroll \& Nuro, 2002; Therien, Lavarenne, \& Lecomte, 2014). 
development of a new lifestyle. In the standard CBT group, the relatives were involved in the same sessions apart from the family module.

The participants were assigned to the groups in order of arrival at the centers, and the assignment was blinded for the participants and the families. The treatments were carried out by a clinical psychologist, extensively trained in the treatment of behavioral addictions, with the supervision of the mental health teams of the collaborating centers and the authors of the study. A comparison between patients completing the PIPATIC program $(n=16)$ and patients completing TAU $(n=15)$ (i.e., pure CBT) was carried out. The first intervention (PIPATIC program) focused the problem in an integrative way and addressed different psychological areas and not only the addiction. The second intervention (TAU) focused on the addiction as a primary problem.

\section{Statistical analyses}

All analyses were carried out using SPSS software version 24. Due to the non-normality of the data, non-parametric tests were utilized, and the non-parametric Mann-Whitney $U$ test for two independent samples was used to compare the results of the treatment between the experimental group and the control group (i.e., the CBT group). In order to compare the changes across the four different points of assessment, nonparametric Friedman tests for repeated measures were used. The effect sizes statistical were calculated. The range for small effects is $0.20-0.50$, for medium effects is $0.50-0.80$, and for large effects is $\geq 0.8$ (Cohen, 1988). The Wilcoxon test was used in a post-hoc Friedman analysis to calculate the effect sizes regarding the changes via the temporal stages (pre- and post-measures). To correct for multiple comparisons, the Bonferroni procedure was applied.

\section{Ethics}

The study was approved by the ethics committees of the mental health centers that participated in the studies (Centro de Salud Mental Infanto Juvenil Joan Obiols of Barcelona, and Consorci Sanitari del Maresme, Mataró) and the research team's ethics committee. The participants and their legal guardians signed consent forms. All the information that could have been used to identify the patients was anonymized. The study procedures were carried out in accordance with the Declaration of Helsinki.

\section{RESULTS}

The participants were all males aged between 12 and 18 years. The experimental group had a mean age of 15.19 years $(S D=1.9)$, whereas the control group had 14.73 years $(S D=1.58)$. All participants were Spanish, and all but two were students during the treatment. None of the participants reported any serious physical health problem, although one participant was currently receiving antidepressant medication. The psychological characteristics of the sample have been described in detail elsewhere (Torres-Rodríguez, Griffiths, Carbonell, \& Oberst, 2018). The participants mostly reported problematic use of the online video games with three participants reporting problematic use of offline video games. The most popular type of online video games in the sample was: massively multiplayer online roleplaying games $(51.6 \%)$, role-playing games $(32.3 \%)$, multiplayer online battle arena games $(64.5 \%)$, shooter games $(64.5 \%)$, sports games $(35.5 \%)$, and others $(2.3 \%)$. A small proportion of the sample also reported problematic use of the internet (19.4\%) and smartphones (9.7\%).

\section{Comparison of experimental and control groups}

Regarding the outcome evaluations in both groups, changes relating to the different interventions were examined with reference to the pre-test and post-test scores in the dependent variables listed above. Before examining the efficacy of each intervention, the measures at $\mathrm{T} 1$ were compared between the experimental and control groups and no significant differences were detected, indicating that the two groups are at the same or similar level of clinical measures at the baseline of the study (Tables 2-4). Features related to IGD are reported in Table 2. Both patients and their families reported similar perceptions. There were no significant differences between either group in the pre-treatment phase. However, in the post-test, the PIPATIC group (compared to the control group) dedicated fewer hours to gaming, and had lower scores in being able to stop gaming, subjective scores relating to engagement/addiction, and IGD-20 scores.

Table 2. Medians and standard deviations (in brackets) of measures regarding video game use and IGD for treatment condition and pre- and post-assessment

\begin{tabular}{|c|c|c|c|c|c|c|c|}
\hline & \multicolumn{3}{|c|}{ Pre-test } & \multicolumn{4}{|c|}{ Post-test } \\
\hline & EG & $\mathrm{CG}$ & $p$ & EG & $\mathrm{CG}$ & $p$ & $r$ \\
\hline Week gaming hours $(\mathrm{P})$ & $51.40(19.21)$ & $43.36(15.51)$ & .384 & $11.15(7.07)$ & $31.80(15.63)$ & .0001 & .707 \\
\hline Week gaming hours $(\mathrm{F})$ & $48.87(17.45)$ & $50.06(19.34)$ & .968 & $14.84(9.16)$ & $32.83(17.93)$ & .001 & .586 \\
\hline Postponement (P) & $4.19(0.65)$ & $4.07(1.03)$ & .966 & $1.81(0.75)$ & $3.27(0.79)$ & .0001 & .702 \\
\hline Postponement (F) & $4.44(0.62)$ & $4.60(0.63)$ & .402 & $2.19(0.91)$ & $3.67(0.97)$ & .0001 & .644 \\
\hline Subjective addiction $(\mathrm{P})$ & $7.75(1.00)$ & $8.27(1.16)$ & .239 & $3.13(1.40)$ & $6.47(1.88)$ & .0001 & .702 \\
\hline Subjective addiction (F) & $8.88(0.88)$ & $9.00(1.00)$ & .663 & $3.69(1.81)$ & $7.33(1.79)$ & .0001 & .708 \\
\hline IGD-20 & $79.75(5.77)$ & $76.13(5.37)$ & .126 & $32.19(7.51)$ & $51.93(16.9)$ & .001 & .554 \\
\hline
\end{tabular}

Note. Bold values indicate significance at $p<.025$ level (obtained with Bonferroni correction). Mann-Whitney $U$ test was used to compare the results between experimental group (EG) and control group (CG). IGD: Internet Gaming Disorder. 
Table 3. Medians and standard deviations (in brackets) of all YSR subscales and total CBCL subscales for treatment condition and pre- and post-assessment

\begin{tabular}{|c|c|c|c|c|c|c|c|}
\hline & \multicolumn{3}{|c|}{ Pre-test } & \multicolumn{4}{|c|}{ Post-test } \\
\hline & EG & CG & $p$ & EG & CG & $p$ & $r$ \\
\hline \multicolumn{8}{|l|}{ Competence scales } \\
\hline Activities & $30.31(6.92)$ & $29.66(5.32)$ & .953 & $36.56(14.22)$ & $34.00(6.21)$ & .405 & \\
\hline Social & 37.25 (18.07) & $32.00(9.72)$ & .403 & $37.75(12.66)$ & $34.86(7.45)$ & .183 & \\
\hline \multicolumn{8}{|l|}{ School $^{\mathrm{a}}$} \\
\hline Total competence scales & $26.92(6.50)$ & $28.93(11.25)$ & .913 & $33.28(13.74)$ & $30.40(6.40)$ & .394 & \\
\hline \multicolumn{8}{|l|}{ Syndrome scales } \\
\hline I - Anxious/depressed & $62.38(8.05)$ & $60.07(9.34)$ & .393 & $53.69(3.96)$ & $58.00(8.08)$ & .230 & \\
\hline II - Withdrawn/depressed & $66.69(7.54)$ & $62.47(11.86)$ & .087 & $56.94(7.33)$ & $59.13(8.91)$ & .631 & \\
\hline III - Somatic complaints & $61.75(10.02)$ & $55.07(5.62)$ & .027 & $51.81(2.92)$ & $54.40(6.53)$ & .549 & \\
\hline IV - Social problems & $61.56(8.28)$ & $61.33(9.75)$ & .827 & $53.19(3.56)$ & $59.67(8.22)$ & .016 & .239 \\
\hline V - Thought problems & $56.63(5.62)$ & $55.87(6.04)$ & .645 & $52.00(2.94)$ & $53.87(4.502)$ & .295 & \\
\hline VI - Attention problems & $63.50(8.60)$ & $66.80(11.59)$ & .633 & $53.25(6.19)$ & 64.33 (14.74) & .003 & .530 \\
\hline VII - Rule-breaking behavior & $55.81(5.63)$ & $57.33(5.97)$ & .402 & $53.69(4.33)$ & $55.87(5.95)$ & .143 & \\
\hline VIII - Aggressive behavior & $58.19(9.88)$ & $62.60(10.83)$ & .147 & $52.69(5.22)$ & $59.80(8.66)$ & .005 & .503 \\
\hline \multicolumn{8}{|l|}{ Total scales } \\
\hline Internalizing problems & $65.38(7.05)$ & $58.27(11.32)$ & .085 & $51.19(6.53)$ & $54.60(12.12)$ & .736 & \\
\hline Externalizing problems & $55.88(7.50)$ & $59.80(8.81)$ & .166 & $47.13(9.04)$ & $57.40(8.63)$ & .005 & .509 \\
\hline Total problems & $62.50(5.30)$ & $61.80(7.36)$ & .781 & $48.75(7.46)$ & $58.73(9.27)$ & .004 & .515 \\
\hline \multicolumn{8}{|l|}{ Total CBCL scales } \\
\hline Internalizing problems & $70.00(6.78)$ & $69.27(11.64)$ & .692 & $59.69(6.86)$ & $64.47(11.44)$ & .190 & \\
\hline Externalizing problems & $59.38(8.15)$ & $64.33(7.97)$ & .052 & $52.56(8.45)$ & $61.53(7.76)$ & .003 & .537 \\
\hline Total problems & $66.94(5.63)$ & $69.33(8.04)$ & .351 & $56.06(7.60)$ & $64.40(8.24)$ & .005 & .501 \\
\hline
\end{tabular}

Note. Bold values indicate significance at $p<.025$ level (obtained with Bonferroni correction). Mann-Whitney $U$ test was used to compare the

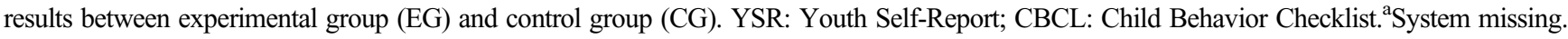

Table 4. Medians and standard deviations (in brackets) of MACI, TMMS subscales, and social abilities scale for treatment condition and preand post-assessment

\begin{tabular}{|c|c|c|c|c|c|c|c|}
\hline & \multicolumn{3}{|c|}{ Pre-test } & \multicolumn{4}{|c|}{ Post-test } \\
\hline & EG & $\mathrm{CG}$ & $p$ & EG & $\mathrm{CG}$ & $p$ & $r$ \\
\hline \multicolumn{8}{|l|}{ MACI's scales } \\
\hline Identity diffusion (A) & $61.60(22.8)$ & $65.30(14.5)$ & .782 & $41.10(20.2)$ & $50.30(26.3)$ & .323 & \\
\hline Self-devaluation (B) & $54.30(19.2)$ & $58.80(22.4)$ & .752 & $42.40(14.4)$ & $57.00(23.6)$ & .044 & \\
\hline Body disapproval (C) & $52.70(18.5)$ & $52.70(24.1)$ & .922 & $50.90(16.0)$ & $57.07(28.3)$ & .678 & \\
\hline \multicolumn{8}{|l|}{ Emotional intelligence } \\
\hline Attention to feelings & $19.60(7.48)$ & $17.20(6.77)$ & .406 & $24.50(7.59)$ & $19.13(6.99)$ & .050 & \\
\hline Clarity of feelings & $22.30(5.16)$ & $21.06(6.91)$ & .329 & $26.44(8.38)$ & $20.33(3.43)$ & .020 & .416 \\
\hline Mood repair & $21.31(6.23)$ & $21.66(3.53)$ & .874 & $28.80(8.47)$ & $23.20(5.28)$ & .045 & \\
\hline \multicolumn{8}{|l|}{ Social abilities } \\
\hline Global scale & $28.81(28.5)$ & $35.80(28.9)$ & .405 & $68.50(30.74)$ & $41.00(37.02)$ & .042 & \\
\hline
\end{tabular}

Note. Bold values indicate significance at $p<.025$ level (obtained with Bonferroni correction). To increase confidence in the results, Bonferroni corrections were used. Nonetheless, there are multiple values smaller than .05 alpha that should be considered for future research. Mann-Whitney $U$ test was used to compare the results between experimental group (EG) and control group (CG). MACI: Millon Adolescent Clinical Inventory; TMMS: Trait Meta-Mood Scale.

There were also significant differences between the two groups regarding comorbid disorders, as well as the behavioral and emotional functioning of the participants from both patients (YSR test) and their relatives (CBCL test). Table 3 demonstrates that all group comparisons were non-significant. However, in the post-test, the experimental group had significantly lower scores in several important areas (social problems, attention problems, aggressive behavior scales, externalizing problems, and total problem scales).
In relation to the CBCL results, no differences between groups were found at baseline treatment. However, at post-treatment, there were statistically significant differences between the two groups including: activities $\left(M_{\mathrm{EG}}=39.56 ; M_{\mathrm{CG}}=30.26 ; U=48.5 ; p<.01\right)$, total competence scale $\quad\left(M_{\mathrm{EG}}=36.23 ; \quad M_{\mathrm{CG}}=27.2 ; \quad U=46.5\right.$; $p<.05)$, rule-breaking behavior $\left(M_{\mathrm{EG}}=54 ; M_{\mathrm{CG}}=58.6\right.$; $U=56.5 ; p<.05)$, aggressive behavior scales $\left(M_{\mathrm{EG}}=55.81\right.$; $\left.M_{\mathrm{CG}}=63.8 ; \quad U=45 ; \quad p<.01\right), \quad$ externalizing problems 
$\left(M_{\mathrm{EG}}=52.56 ; M_{\mathrm{CG}}=61.53 ; U=44.5 ; p<.01\right)$, and total problem scales $\left(M_{\mathrm{EG}}=56.06 ; M_{\mathrm{CG}}=64.40 ; \quad U=49.5\right.$; $p<.01$ ) (Table 3 ). In addition, the PIPATIC program generally had lower median scores even if they were not significantly different. In addition, it is noteworthy that in the MACI's scale "suicidal tendency" (GG) showed a statistically significant difference in both groups at posttreatment $\left(M_{\mathrm{EG}}=32.8 ; M_{\mathrm{CG}}=48.7 ; U=58 ; p<.01\right)$.

The findings in relation to the intrapersonal and interpersonal abilities are presented in Table 4. Regarding the intrapersonal abilities assessed by three MACI subscales and the TMMS test for emotional intelligence, significant group differences were found in the post-test for clarity of feelings (subscale of TMMS test). Nonetheless, self-devaluation (B) scale and the two of three emotional intelligence scales (attention to feelings and mood repair) presented smaller values than 0.05 . With respect to the interpersonal and social abilities, no significant group differences were found at posttreatment assessment because of the Bonferroni correction. Concerning family discord $(\mathrm{G})$, no significant differences were found at T1 $(U=96.5 ; p>.05)$. However, the results demonstrated there was a significant group difference in family discord $(U=49 ; p<.01)$ at post-assessment, with an improvement in PIPATIC group.

Finally, in relation to the therapists' measures, no significant differences were found in CGI $(U=120 ; p>.05)$ and GAF $(U=93 ; p>.05)$ between both groups at baseline. At post-treatment, significant differences were found between groups for CGI $(U=18.5 ; p<.001)$ and GAF $(U=10$; $p<.001$ ) with the PIPATIC group demonstrating better scores than the control group. The WATOCI variables were analyzed only at post-treatment assessment, because it is a scale that needs to be applied once the treatment has been completed. The results demonstrated statistically significant differences between both groups at the following WATOCI scales (Table 5): tasks, bond, goals, theory of change, and total score. On all these measures, the PIPATIC group had better scores than the control group on these scales demonstrating that the PIPATIC treatment was more effective than CBT alone. The only subscale where there was no significant difference was the bond between therapist and the patient (i.e., patients in both groups bonded equally well with their therapists).

\section{Effects of the IGD treatment process}

As shown in Table 6, all participants in the experimental group demonstrated a decrease over time in all measures related to gaming and addiction. This effect was significant, and maintained stability in the follow-up assessment. The control group also presented significant changes in postponement, patient's subjective addiction score, family's subjective addiction score, and IGD-20 results. The analysis was carried out examining the comorbid symptoms plus the contribution of the interventions regarding behavioral and emotional functioning from both patients' and relatives' perspective (Table 7 for patients and Table 8 for families). For the patients, the PIPATIC group demonstrated a significant decrease in all the YSR scales (apart from the social competence scale), as did their relatives (CBCL). The parents of the control group had perceptions similar to parents of the PIPATIC group, and reported that the patients had improved with respect to some areas (i.e., anxious/depressed, attention problems, aggressive behavior, and total problems).

Table 5. Medians and standard deviations (in brackets) of WATOCI dependent variables for treatment condition at post-assessment

\begin{tabular}{lcccc}
\hline & EG & CG & $p$ & $r$ \\
\hline Tasks & $25.68(2.44)$ & $19.26(1.98)$ & $\mathbf{. 0 0 0 1}$ & .788 \\
Bond & $25.50(3.32)$ & $25.13(2.58)$ & .545 & .001 \\
Goals & $25.06(2.08)$ & $19.60(3.20)$ & .0001 & .703 \\
Theory of change & $32.00(3.52)$ & $26.40(3.64)$ & $\mathbf{. 0 0 0 1}$ & .625 \\
Total & $108.25(10.47)$ & $90.40(7.07)$ & .650 \\
\hline
\end{tabular}

Note. Bold values indicate significance at $p<.025$ level (obtained with Bonferroni correction). Mann-Whitney $U$ test was used to compare the results between experimental group (EG) and control group (CG). WATOCI: Working Alliance Theory of Change Inventory.

Table 6. Medians of variables regarding video game use and IGD for treatment condition

\begin{tabular}{|c|c|c|c|c|c|c|c|c|c|c|c|c|}
\hline & \multicolumn{6}{|c|}{ EG } & \multicolumn{6}{|c|}{ CG } \\
\hline & $\mathrm{T} 1$ & $\mathrm{~T} 2$ & $\mathrm{~T} 3$ & $\mathrm{~T} 4$ & $p$ & $r$ & $\mathrm{~T} 1$ & $\mathrm{~T} 2$ & $\mathrm{~T} 3$ & $\mathrm{~T} 4$ & $p$ & $r$ \\
\hline Week gaming hours $(\mathrm{P})$ & 51.40 & 19.03 & 11.15 & 11.40 & .0001 & .879 & 44.63 & 32.50 & 29.22 & 34.13 & .013 & \\
\hline Week gaming hours $(\mathrm{F})$ & 48.87 & 20.25 & 14.84 & 11.75 & .0001 & .879 & 52.63 & 36.09 & 31.86 & 46.59 & .032 & \\
\hline Postponement (P) & 4.19 & 2.50 & 1.81 & 1.81 & .0001 & .900 & 4.07 & 3.27 & 3.27 & 3.13 & .030 & \\
\hline Postponement (F) & 4.44 & 2.44 & 2.19 & 2.25 & .0001 & .891 & 3.40 & 2.47 & 2.17 & 1.97 & .002 & .644 \\
\hline Subjective addiction $(\mathrm{P})$ & 7.75 & 5.06 & 3.13 & 2.44 & .0001 & .886 & 8.27 & 7.07 & 6.47 & 6.07 & .001 & .670 \\
\hline Subjective addiction (F) & 8.88 & 6.06 & 3.69 & 2.94 & .0001 & .883 & 9.00 & 7.53 & 7.33 & 6.73 & .0001 & .679 \\
\hline IGD-20 & 79.75 & 46.31 & 32.19 & 30.69 & .0001 & .879 & 76.13 & 62.60 & 51.93 & 56.40 & .0001 & .879 \\
\hline
\end{tabular}

Note. Bold values indicate significance at $p<.025$ level (obtained with Bonferroni correction). The effect sizes were statistically significant using T1 and T3 measures (pre- and post-). To increase confidence in the results, Bonferroni corrections were used. Nonetheless, there are multiple values regarding the control group smaller than .05 alpha that should be considered for future research. Friedman test for repeated measures was used for comparison between pre-, middle-, and post-treatment and 3-month follow-up assessment. EG: experimental group; CG: control group; IGD: Internet Gaming Disorder. 
Table 7. Medians of YSR subscales for treatment condition

\begin{tabular}{|c|c|c|c|c|c|c|c|c|c|}
\hline & \multicolumn{5}{|c|}{ EG } & \multicolumn{4}{|c|}{$\mathrm{CG}$} \\
\hline & $\mathrm{T} 1$ & $\mathrm{~T} 3$ & $\mathrm{~T} 4$ & $p$ & $r$ & $\mathrm{~T} 1$ & $\mathrm{~T} 3$ & $\mathrm{~T} 4$ & $p$ \\
\hline \multicolumn{10}{|l|}{ Competence scales } \\
\hline Activities & 30.31 & 36.56 & 43.81 & .0001 & .426 & 29.21 & 33.64 & 30.14 & .233 \\
\hline Social & 37.25 & 37.75 & 40.06 & .024 & & 30.57 & 34.57 & 32.71 & .030 \\
\hline Total competence scales & 27.00 & 35.84 & 40.15 & .003 & .550 & 28.14 & 30.07 & 27.35 & .316 \\
\hline \multicolumn{10}{|l|}{ Syndrome scales } \\
\hline I - Anxious/depressed & 62.38 & 53.69 & 52.69 & .0001 & .778 & 60.07 & 58.00 & 59.73 & .571 \\
\hline II - Withdrawn/depressed & 66.69 & 56.94 & 55.13 & .0001 & .815 & 62.47 & 59.13 & 60.73 & .141 \\
\hline III - Somatic complaints & 61.75 & 51.81 & 51.69 & .0001 & .781 & 55.07 & 54.40 & 55.47 & .607 \\
\hline IV - Social problems & 61.56 & 53.19 & 51.82 & .0001 & .767 & 61.33 & 59.67 & 59.67 & .498 \\
\hline V - Thought problems & 56.63 & 52.00 & 50.13 & .0001 & .718 & 55.87 & 53.87 & 53.53 & .038 \\
\hline VI - Attention problems & 63.50 & 53.25 & 53.00 & .0001 & .802 & 66.80 & 64.33 & 64.53 & .484 \\
\hline VII - Rule-breaking behavior & 5.81 & 53.69 & 52.38 & .002 & .455 & 57.33 & 55.87 & 57.93 & .334 \\
\hline VIII - Aggressive behavior & 58.19 & 52.69 & 52.56 & .0001 & .796 & 62.60 & 59.80 & 61.67 & .793 \\
\hline \multicolumn{10}{|l|}{ Total scales } \\
\hline Internalizing problems & 65.38 & 51.19 & 49.13 & .0001 & .853 & 58.27 & 54.60 & 57.87 & .262 \\
\hline Externalizing problems & 55.88 & 47.13 & 45.94 & .0001 & .854 & 59.80 & 57.40 & 60.07 & .368 \\
\hline Total problems & 62.50 & 48.75 & 46.25 & .0001 & .879 & 61.80 & 58.70 & 60.07 & .395 \\
\hline
\end{tabular}

Note. Bold values indicate significance at $p<.025$ level (obtained with Bonferroni correction). The effect sizes statistically significant using T1 and T3 measures (pre- and post-). Friedman test for repeated measures was used for comparison between pre- and post-treatment and 3-month follow-up assessment. EG: experimental group; CG: control group; YSR: Youth Self-Report.

Table 8. Medians of CBCL subscales for treatment condition

\begin{tabular}{|c|c|c|c|c|c|c|c|c|c|c|}
\hline & \multicolumn{5}{|c|}{ EG } & \multicolumn{5}{|c|}{ CG } \\
\hline & $\mathrm{T} 1$ & $\mathrm{~T} 3$ & $\mathrm{~T} 4$ & $p$ & $r$ & $\mathrm{~T} 1$ & $\mathrm{~T} 3$ & $\mathrm{~T} 4$ & $p$ & $r$ \\
\hline \multicolumn{11}{|l|}{ Competence scales } \\
\hline Activities & 25.68 & 39.56 & 44.56 & .0001 & .866 & 28.85 & 29.64 & 29.07 & .486 & \\
\hline Social & 29.40 & 39.53 & 43.53 & .0001 & .835 & 31.85 & 34.28 & 34.78 & .620 & \\
\hline School & 36.61 & 42.69 & 44.92 & .001 & .658 & 37.35 & 38.71 & 39.85 & .358 & \\
\hline Total competence scales & 22.23 & 36.23 & 42.00 & .0001 & .780 & 24.92 & 26.64 & 27.07 & .678 & \\
\hline \multicolumn{11}{|l|}{ Syndrome scales } \\
\hline I - Anxious/depressed & 65.44 & 56.94 & 53.75 & .0001 & .745 & 66.80 & 60.67 & 60.33 & .006 & .616 \\
\hline II - Withdrawn/depressed & 78.88 & 63.69 & 61.56 & .0001 & .834 & 77.33 & 71.87 & 68.20 & .034 & \\
\hline III - Somatic complaints & 64.25 & 56.06 & 55.44 & .002 & .630 & 62.73 & 61.13 & 63.27 & .059 & \\
\hline IV - Social problems & 30.25 & 55.13 & 54.69 & .0001 & .770 & 64.53 & 61.20 & 58.67 & .140 & \\
\hline $\mathrm{V}$ - Thought problems & 64.88 & 55.69 & 54.38 & .0001 & .796 & 65.00 & 60.33 & 58.73 & .184 & \\
\hline VI - Attention problems & 61.81 & 56.44 & 55.06 & .0001 & .696 & 70.20 & 64.33 & 62.27 & .007 & .604 \\
\hline VII - Rule-breaking behavior & 58.06 & 54.00 & 53.44 & .0001 & .605 & 61.13 & 58.60 & 60.27 & .058 & \\
\hline VIII - Aggressive behavior & 61.06 & 55.81 & 54.19 & .006 & .566 & 67.20 & 63.80 & 61.67 & .009 & .414 \\
\hline \multicolumn{11}{|l|}{ Total scales } \\
\hline Internalizing problems & 70.00 & 59.69 & 57.19 & .0001 & .841 & 69.27 & 64.47 & 64.67 & .071 & \\
\hline Externalizing problems & 59.38 & 52.56 & 49.38 & .0001 & .608 & 64.33 & 61.53 & 60.87 & .059 & \\
\hline Total problems & 66.94 & 56.06 & 53.56 & .0001 & .808 & 69.33 & 64.40 & 63.87 & .017 & .657 \\
\hline
\end{tabular}

Note. Bold values indicate significance at $p<.025$ level (obtained with Bonferroni correction). The effect sizes were statistically significant using T1 and T3 measures (pre- and post-). Friedman test for repeated measures was used comparison between pre- and post-treatment and 3-month follow-up assessment. EG: experimental group; CG: control group; CBCL: Child Behavior Checklist.

With reference to intrapersonal abilities, the significant differences between both groups were observed (Table 9). Participants in the experimental group showed an improvement regarding identity, self-esteem, emotional intelligence, and social abilities. The control group only showed a significantly higher attention to their feelings. Concerning family discord $(\mathrm{G})$, no significant change was found in the control group $\left(M_{\mathrm{T} 1}=58.73 ; M_{\mathrm{T} 3}=63.73 ; M_{\mathrm{T} 4}=66.53\right.$; $\left.\chi^{2}=1.32 ; p>.05\right)$, but was significant in the PIPATIC group $\left(M_{\mathrm{T} 1}=52.19 ; M_{\mathrm{T} 3}=43.37 ; M_{\mathrm{T} 4}=36.88 ; \chi^{2}=8.66\right.$; $p<.05$ ). Finally, in relation to the therapists' measures, significant changes across the assessment period were found. The PIPATIC group $\left(M_{\mathrm{T} 1}=5 ; M_{\mathrm{T} 3}=1.88 ; M_{\mathrm{T} 4}=\right.$ $\left.1.25 ; \chi^{2}=45.92 ; p<.001\right)$ and the control group $\left(M_{\mathrm{T} 1}=5\right.$; $\left.M_{\mathrm{T} 3}=3.87 ; M_{\mathrm{T} 4}=3.47 ; \chi^{2}=28.73 ; p<.001\right)$ demonstrated a significant reduction of the mental illness severity 
Table 9. Medians of MACI, Emotional Intelligence, and Social Abilities subscales for treatment condition

\begin{tabular}{|c|c|c|c|c|c|c|c|c|c|}
\hline & \multicolumn{5}{|c|}{$\mathrm{EG}$} & \multicolumn{4}{|c|}{$\mathrm{CG}$} \\
\hline & $\mathrm{T} 1$ & $\mathrm{~T} 3$ & $\mathrm{~T} 4$ & $p$ & $r$ & $\mathrm{~T} 1$ & $\mathrm{~T} 3$ & $\mathrm{~T} 4$ & $p$ \\
\hline \multicolumn{10}{|l|}{ MACI's scales } \\
\hline Identity diffusion (A) & 61.63 & 41.19 & 37.38 & .030 & .695 & 65.33 & 50.33 & 56.60 & .175 \\
\hline Self-devaluation (B) & 54.31 & 42.44 & 32.94 & .001 & .532 & 58.87 & 57.00 & 59.07 & .859 \\
\hline Body disapproval (C) & 52.75 & 50.94 & 38.19 & .084 & & 52.73 & 57.07 & 54.20 & .155 \\
\hline \multicolumn{10}{|l|}{ Emotional intelligence } \\
\hline Attention to feelings & 19.68 & 24.50 & 27.68 & .002 & .533 & 17.20 & 19.13 & 20.80 & .026 \\
\hline Clarity of feelings & 22.37 & 26.44 & 31.31 & .001 & .355 & 21.06 & 20.33 & 20.60 & .748 \\
\hline Mood repair & 21.31 & 28.81 & 30.62 & .013 & .660 & 21.66 & 23.27 & 23.00 & .516 \\
\hline \multicolumn{10}{|l|}{ Social abilities } \\
\hline Global scale & 28.81 & 68.50 & 75.75 & .0001 & .852 & 35.8 & 41.60 & 35.20 & .250 \\
\hline
\end{tabular}

Note. Bold values indicate significance at $p<.025$ level (obtained with Bonferroni correction). The effect sizes were statistically significant using T1 and T3 measures (pre- and post-). Friedman test for repeated measures was used comparison between pre- and post-treatment and 3month follow-up assessment. EG: experimental group; CG: control group; MACI: Millon Adolescent Clinical Inventory.

(CGI-SI) of the participants. In relation to the global activity (GAF), both groups experienced an improvement: PIPATIC group $\left(M_{\mathrm{T} 1}=47.38 ; M_{\mathrm{T} 3}=82.81 ; M_{\mathrm{T} 4}=86.69 ; \chi^{2}=45.07 ;\right.$ $p<.001)$ and control group $\left(M_{\mathrm{T} 1}=42.87 ; M_{\mathrm{T} 3}=62.8\right.$ $\left.M_{\mathrm{T} 4}=63.13 ; \chi^{2}=36.41 ; p<.001\right)$.

\section{DISCUSSION}

This study evaluated the effects of the PIPATIC program on a number of key variables and compared these with the effects of a standard CBT (TAU) control group. The variables were assessed at baseline, during the middle of the treatment, immediately after treatment, and at a 3-month follow-up. The measures were completed by participants, their relatives, and their therapists in an effort to triangulate the findings. More specifically, the study evaluated the effects and changes regarding IGD symptoms, psychopathological and comorbid symptoms, emotional intelligence, self-esteem, social skills, family environment, therapeutic alliance, and change perceptions, by comparing standard CBT with the newly developed PIPATIC program.

The main findings of the comparative evaluation can be summarized as follows: (a) both groups experienced a significant reduction of symptoms regarding IGD, but those individuals in the PIPATIC group demonstrated more statistically significant changes than control group; (b) the PIPATIC group demonstrated significant reductions in comorbid symptoms as reported by the patients and their relatives. Moreover, the treatment program improved their identity diffusion, self-devaluation, emotional intelligence, social abilities, and reduced family conflict. In contrast, the control group experienced positive significant changes in anxiety, attention problems, aggressive behavior, and overall problems reported by relatives (CBCL). However, the improvements (based on the effect sizes) were less than that of the PIPATIC group; (c) most of the PIPATIC patients experienced a decrease of negative symptoms during the middle of the treatment (T2) at the 11th session; and (d) the changes achieved with the PIPATIC program and for those undergoing standard CBT demonstrated continued stability 3 months after the end of the respective treatment.
The differences between both interventions can be summarized in the following aspects: (a) no significant differences were found between the two groups concerning the IGD variables at baseline treatment; (b) the results at posttreatment demonstrated significant differences between the two groups in the number of weekly gaming hours, IGD symptoms, comorbidity disorders, externalizing problems, overall total problems, emotional intelligence, and the family relationships (with those in the PIPATIC program demonstrating more improved scores on these aspects compared to those given standard CBT); (c) apart from the bond between patient and therapist, those undergoing the PIPATIC treatment (compared to the control group) found the treatment more satisfying; (d) significant differences between groups were found in measures completed by the therapists in the post-treatment phase (CGI and GAF scales); and (e) the PIPATIC program demonstrated a greater reduction than CBT treatment in IGD symptoms and improvement of abilities.

This study described the effects of a practical clinical trial of psychotherapeutic approaches for adolescents with IGD. The aim of PIPATIC program is to offer specialized psychotherapy for adolescents with symptoms of IGD and accompanying comorbid disorders. The other aims of the program were to help improve interpersonal and intrapersonal abilities and apply family therapy. Its program seeks to reestablish the adolescent's well-being and to reintegrate the individual back into a normal life including the controlled use of video games and internet. It is noteworthy that this is an intervention model based on an integration of previous research findings.

The findings of this study corroborate the importance of extending psychotherapeutic work into comorbid disorders in addition to addressing IGD itself. Previous research has consistently found an association between high levels of distress and online addictions (Mentzoni et al., 2011; Yan, $\mathrm{Li}$, \& Sui, 2014), and high rates of comorbid psychiatric disorders (Andreassen et al., 2016; Bozkurt, Coskun, Ayaydin, Adak, \& Zoroglu, 2013; Ferguson et al., 2011; Müller, Beutel, Egloff, \& Wölfling, 2014). The findings regarding the participation of the family are warranted and according to the idea that intervention programs for 
adolescents need to include parents actively in the therapy (Liu et al., 2015; Young, 2009). This is especially relevant given that family conflict and poor family relationships cooccur in adolescent IGD (Bonnaire \& Phan, 2017). In this study, as in others (Winkler et al., 2013), a CBT approach was effective in treating IGD symptoms (although more so when individuals were assigned to the PIPATIC program).

Finally, some limitations of this study should be noted and therefore generalization of the present results should be considered with caution. First, the self-report data included potential sources of error (e.g., social desirability bias and memory recall bias). Moreover, the multiple self-assessment tools used have the potential to lead to a type-I error (given how many different variables were evaluated). Nevertheless, the data collection was supervised by a trained psychologist to ensure the highest quality of data that was also based on clinical interviews. Moreover, Bonferroni test was used to overcome type-I errors increasing confidence in results obtained. The psychometric tools used demonstrated adequate psychometric properties and they had all been previously psychometrically validated using Spanish populations. In addition, the inclusion of a follow-up provided an opportunity to explore the effects and stability of the therapy observed months after the treatment. On the other hand, all the data were self-report, although the inclusion of corroborating data from relatives increased the veracity of the data collected. Second, the sample size is relatively small. However, many other treatment studies report a similar (or even smaller) sample size (Dell'Osso et al., 2008; Kim, 2008; Pallesen, Lorvik, Bu, \& Molde, 2015; Wölfling et al., 2014; Yao et al., 2017; Zhang et al., 2016). Third, there was no randomization of participants being assigned to treatment groups, because all participants were assigned to one of the two groups in order of arrival of seeking help for IGD at the treatment centers. Fourth, the lack of a traditional control group without treatment (waiting list) was not utilized, because it was unethical to deny treatment to those who sought treatment for IGD at the treatment centers. In future, and if deemed ethical, studies should include a wait-list control group without any intervention. However, the use of a TAU control group is a valuable element of this study that allowed statistical comparisons and explored the effects of the both interventions. Fifth, the participants were all Spanish male adolescents; therefore, it is not known whether the PIPATIC treatment would be equally effective for females, adults, and/or individuals from other countries and cultures. Due to the study design, it was not possible to determine the efficacy of each intervention compared to no treatment, although as noted earlier in the paper, previous studies have shown CBT to be effective compared to non-treatment (Greenfield, 1999; Griffiths \& Meredith, 2009; Kaptsis et al., 2016; King et al., 2010, 2011; Young, 2007, 2013).

\section{CONCLUSIONS}

Based on the findings of this study, the PIPATIC program presented significant positive effects regarding the treatment of the IGD and its comorbid disorders/symptoms, alongside statistically significant improvements of intra- and interpersonal abilities and family relationships. However, it should also be noted that standard CBT also demonstrated positive significant effects in the treatment of IGD, but reductions regarding the most of the comorbid disorders and improvements in other areas of life functioning were not statistically significant. Changing the focus of treatment and applying the integrative focus of the PIPATIC treatment (including the addiction, the comorbid symptoms, intrapersonal and interpersonal abilities, and family psychotherapy) appeared to generate greater improvements for facilitating adolescent behavior change than the therapy focusing only on the IGD itself (i.e., CBT).

Funding sources: This study was supported by personal Blanquerna Research Grant (BRB) to AT-R.

Authors' contribution: AT-R: study concept and design, access to the sample, analysis and interpretation of data, writing, and review. MDG and XC: study concept and design, writing, and review. UO: analysis and interpretation of data, writing, and review. All authors had full access to all data in the study and take responsibility for the integrity of the data and the accuracy of the data analysis.

Conflict of interest: The authors report no financial or other relationship relevant to the subject of this article.

Acknowledgements: The authors would like to thank all the participants and their families.

\section{REFERENCES}

Achenbach, T. M., \& Rescorla, L. A. (2001). Manual for the ASEBA school-age forms \& profiles. Burlington, VT: ASEBA.

American Psychiatric Association [APA]. (2002). Diagnostic and statistical manual of mental disorders (DSM-IV-TR) (4th ed., text rev.). Barcelona, Spain: Masson.

American Psychiatric Association [APA]. (2013). Diagnostic and statistical manual of mental disorders (DSM-5) (5th ed.). Washington, DC: American Psychiatric Association.

Andreassen, C. S., Billieux, J., Griffiths, M. D., Kuss, D. J., Demetrovics, Z., Mazzoni, E., \& Pallesen, S. (2016). The relationship between addictive use of social media and video games and symptoms of psychiatric disorders: A large-scale cross-sectional study. Psychology of Addictive Behaviors, 30(2), 252-262. doi:10.1037/adb0000160

Bonnaire, C., \& Phan, O. (2017). Relationships between parental attitudes, family functioning and Internet gaming disorder in adolescents attending school. Psychiatry Research, 255, 104-110. doi:10.1016/j.psychres.2017.05.030

Bozkurt, H., Coskun, M., Ayaydin, H., Adak, I., \& Zoroglu, S. S. (2013). Prevalence and patterns of psychiatric disorders in referred adolescents with Internet addiction. Psychiatry and Clinical Neurosciences, 67(5), 352-359. doi:10.1111/pcn. 12065

Busner, J., \& Targum, S. (2007). The Clinical Global Impressions Scale: Applying a research tool in clinical practice. Psychiatry (Edgmont), 4(7), 28-37. 
Carroll, K. M., \& Nuro, K. F. (2002). One size cannot fit all: A stage model for psychotherapy manual development. Clinical Psychology: Science and Practice, 9(4), 396-406. doi:10.1093/ clipsy.9.4.396

Chan, P. A., \& Rabinowitz, T. (2006). A cross-sectional analysis of video games and attention deficit hyperactivity disorder symptoms in adolescents. Annals of General Psychiatry, 5(1), 16-26. doi:10.1186/1744-859X-5-16

Cohen, J. (1988). Statistical power analysis for the behavioral sciences (2nd ed.). Hillsdale, NJ: Lawrence Erlbaum Associates.

Corbella, S., \& Botella, L. (2004). Psychometric properties of the Spanish version of the Working Alliance Theory of Change Inventory (WATOCI). Psicothema, 16(4), 702-705.

Dell'Osso, B., Hadley, S., Allen, A., Baker, B., Chaplin, W. F., \& Hollander, E. (2008). Escitalopram in the treatment of impulsive-compulsive Internet usage disorder: An open-label trial followed by a double-blind discontinuation phase. Journal of Clinical Psychiatry, 69(3), 452-456. doi:10.4088/JCP. v69n0316

Du, Y., Jiang, W., \& Vance, A. (2010). Longer term effect of randomized, controlled group cognitive behavioral therapy for Internet addiction in adolescent students in Shanghai. Australian and New Zealand Journal of Psychiatry, 44(2), 129-134. doi: $10.3109 / 00048670903282725$

Ferguson, C., Coulson, M., \& Barnett, J. (2011). A meta-analysis of pathological gaming prevalence and comorbidity with mental health, academic and social problems. Journal of Psychiatric Research, 45(12), 1573-1578. doi:10.1016/j.jpsychires. 2011.09.005

Fernandez-Berrocal, P., Extremera, N., \& Ramos, N. (2004). Validity and reliability of the Spanish modified version of the Trait Meta-Mood Scale. Psychological Reports, 94(3), 751-755. doi:10.2466/pr0.94.3.751-755

Fuster, H., Carbonell, X., Pontes, H. M., \& Griffiths, M. D. (2016). Spanish validation of the Internet Gaming Disorder (IGD-20) Test. Computers in Human Behavior, 56, 215-224. doi:10.1016/j.chb.2015.11.050

Gentile, D., Choo, H., Liau, A., Sim, T., Li, D., Fung, D., \& Khoo, A. (2011). Pathological video game use among youths: A twoyear longitudinal study. Pediatrics, 127(2), e319-e329. doi:10.1542/peds.2010-1353

Gismero, E. (2000). EHS Escala de Habilidades Sociales [EHS Social Skills Scale]. Madrid, Spain: TEA.

Greenfield, D. N. (1999). Virtual addiction: Help for netheads, cyberfreaks, and those who love them. Oakland, CA: New Harbin.

Griffiths, M. D. (2008). Videogame addiction: Further thoughts and observations. International Journal of Mental Health and Addiction, 6(2), 182-185. doi:10.1007/s11469-007-9128-y

Griffiths, M. D., \& Meredith, A. (2009). Videogame addiction and its treatment. Journal of Contemporary Psychotherapy, 39(4), 247-253. doi:10.1007/s10879-009-9118-4

Han, D. H., Lee, Y. S., Shi, X., \& Renshaw, P. F. (2014). Proton magnetic resonance spectroscopy (MRS) in on-line game addiction. Journal of Psychiatric Research, 58, 63-68. doi:10.1016/j.jpsychires.2014.07.007

Hansen, N. B., \& Lambert, M. J. (2003). An evaluation of the doseresponse relationship in naturalistic treatment settings using survival analysis. Mental Health Services Research, 5(1), 1-12. doi:10.1023/A:1021751307358
Hofmann, S. G., \& Barlow, D. H. (2014). Evidence-based psychological interventions and the common factors approach: The beginnings of a rapprochement? Psychotherapy, 51(4), 510-513. doi: $10.1037 / \mathrm{a} 0037045$

Horvath, A. O., \& Greenberg, L. S. (1989). Development and validation of the Working Alliance Inventory. Journal of Counseling Psychology, 36(2), 223-233. doi:10.1037/00220167.36.2.223

Huang, X., Li, M., \& Tao, R. (2010). Treatment of Internet addiction. Current Psychiatry Reports, 12(5), 462-470. doi:10. 1007/s11920-010-0147-1

Kadera, S. W., Lambert, M. J., \& Andrews, A. A. (1996). How much therapy is really enough?: A session-by-session analysis of the psychotherapy dose-effect relationship. Journal of Psychotherapy Practice and Research, 5(2), 132-151.

Kaptsis, D., King, D. L., Delfabbro, P. H., \& Gradisar, M. (2016). Withdrawal symptoms in Internet gaming disorder: A systematic review. Clinical Psychology Review, 43, 58-66. doi:10.1016/j.cpr.2015.11.006

Kelleci, M., \& Inal, S. (2010). Psychiatric symptoms in adolescents with Internet use: Comparison without Internet use. Cyberpsychology, Behavior, and Social Networking, 13(2), 191-194. doi:10.1089/cyber.2009.0026

Kim, E. J., Namkoong, K., Ku, T., \& Kim, S. J. (2008). The relationship between online game addiction and aggression, self-control and narcissistic personality traits. European Psychiatry, 23(3), 212-218. doi:10.1016/j.eurpsy.2007.10.010

Kim, J. U. (2008). The effect of a R/T group counseling program on the Internet addiction level and self-esteem of Internet addiction university students. International Journal of Reality Therapy, 27(2), 4-12.

Kim, K., Ryu, E., Chon, M. Y., Yeun, E. J., Choi, S. Y., Seo, J. S., \& Nam, B. W. (2006). Internet addiction in Korean adolescents and its relation to depression and suicidal ideation: A questionnaire survey. International Journal of Nursing Studies, 43(2), 185-192. doi:10.1016/j.ijnurstu.2005.02.005

King, D., Delfabbro, P., \& Griffiths, M. (2010). Cognitive behavioral therapy for problematic video game players: Conceptual considerations and practice issues. Journal of Cyber Therapy and Rehabilitation, 3(3), 261-273.

King, D., Delfabbro, P., Griffiths, M., \& Gradisar, M. (2011). Assessing clinical trials of Internet addiction treatment: A systematic review and CONSORT evaluation. Clinical Psychology Review, 31(7), 1110-1116. doi:10.1016/j.cpr.2011. 06.009

King, D. L., \& Delfabbro, P. H. (2017). Features of parent-child relationships in adolescents with Internet gaming disorder. International Journal of Mental Health and Addiction, 15(6), 1270-1283. doi:10.1007/s11469-016-9699-6

King, D. L., Delfabbro, P. H., \& Griffiths, M. D. (2013). Trajectories of problem video gaming among adult regular gamers: An 18-month longitudinal study. Cyberpsychology, Behavior and Social Networking, 16(1), 72-76. doi:10.1089/cyber. 2012.0062

King, D. L., Delfabbro, P. H., Wu, A. M. S., Doh, Y. Y., Kuss, D. J., Pallesen, S., Mentzoni, R., Carragher, N., \& Sakuma, H. (2017). Treatment of Internet gaming disorder: An international systematic review and CONSORT evaluation. Clinical Psychology Review, 54, 123-133. doi:10.1016/j.cpr.2017.04.002

Kleinke, C. L. (1994). Common principles of psychotherapy. Pacific Grove, CA: Brooks/Cole Pub Co. 
Ko, C. H., Yen, J. Y., Chen, C. C., Chen, S. H., Wu, K., \& Yen, C. F. (2006). Tridimensional personality of adolescents with Internet addiction and substance use experience. Canadian Journal of Psychiatry, 51(14), 887-894. doi:10.1177/ 070674370605101404

Kuss, D. J., \& Griffiths, M. D. (2012). Online gaming addiction in children and adolescents: A review of empirical research. Journal of Behavioral Addictions, 1(1), 3-22. doi:10.1556/ JBA.1.2012.1.1

Kuss, D., van Rooij, A., Shorter, G. W., Griffiths, M. D., \& van de Mheen, D. (2013). Internet addiction in adolescents: Prevalence and risk factors. Computers in Human Behavior, 29(5), 1987-1996. doi:10.1016/j.chb.2013.04.002

Lambert, M. J., \& Bergin, A. E. (1994). The effectiveness of psychotherapy. Oxford, UK: John Wiley.

Laska, K. M., Gurman, A. S., \& Wampold, B. E. (2014). Expanding the lens of evidence-based practice in psychotherapy: A common factors perspective. Psychotherapy, 51(4), 467-481. doi: $10.1037 / \mathrm{a} 0034332$

Lemmens, J. S., Valkenburg, P. M., \& Peter, J. (2011). Psychosocial causes and consequences of pathological gaming. Computers in Human Behavior, 27(1), 144-152. doi:10.1016/j. chb.2010.07.015

Lemos, S., Fidalgo, A. M., Calvo, P., \& Menéndez, P. (1992). Validación de la escala de psicopatología infanto-juvenil YSR [YSR Infant-Juvenile Psychopathology Scale validation]. Clinica y Salud, 3(2), 183-194.

Liebert, M. A., Lo, S., Ph, D., Wang, C., \& Fang, W. (2005). Physical interpersonal relationships and social anxiety. CyberPsychology \& Behavior, 8(1), 15-20. doi:10.1089/ cpb.2005.8.15

Liu, Q. X., Fang, X. Y., Yan, N., Zhou, Z. K., Yuan, X. J., Lan, J., \& Liu, C. Y. (2015). Multi-family group therapy for adolescent Internet addiction: Exploring the underlying mechanisms. $A d-$ dictive Behaviors, 42, 1-8. doi:10.1016/j.addbeh.2014.10.021

Martín-Fernández, M., Matalí, J. L., García-Sánchez, S., Pardo, M., \& Castellano-Tejedor, C. (2016). Adolescentes con Trastorno por juego en Internet (IGD): Perfiles y respuesta al tratamiento [Adolescents with Internet gaming disorder: Profiles and treatment response]. Adicciones, 29(2), 125-133. doi:10.20882/adicciones. 890

Mentzoni, R. A., Brunborg, G. S., Molde, H., Myrseth, H., Skouverøe, K. J. M., Hetland, J., \& Pallesen, S. (2011). Problematic video game use: Estimated prevalence and associations with mental and physical health. Cyberpsychology, Behavior, and Social Networking, 14(10), 591-596. doi:10.1089/cyber.2010.0260

Millon, T. (1994). Millon Adolescent Clinical Inventory (MACI). Minneapolis, MN: Nacional Computers Systems.

Millon, T. (2004). MACI: Inventario Clínico para Adolescente [MACI Clinical Inventory for Adolescents]. Madrid, Spain: TEA Ediciones.

Müller, K. W., Beutel, M. E., Egloff, B., \& Wölfling, K. (2014). Investigating risk factors for Internet gaming disorder: A comparison of patients with addictive gaming, pathological gamblers and healthy controls regarding the big five personality traits. European Addiction Research, 20(3), 129-136. doi:10.1159/000355832

Pallesen, S., Lorvik, I. M., Bu, E. H., \& Molde, H. (2015). An exploratory study investigating the effects of treatment manual for video game addiction. Psychological Reports:
Mental \& Physical Health, 117(2), 490-495. doi:10.2466/ 02.PR0.117c14z9

Pontes, H. M., Király, O., Demetrovics, Z., \& Griffiths, M. D. (2014). The conceptualisation and measurement of DSM-5 Internet gaming disorder: The development of the IGD-20 Test. PLoS One, 9(10), e110137. doi:10.1371/journal.pone. 0110137

Rehbein, F., Psych, G., Kleimann, M., Mediasci, G., \& Mößle, T. (2010). Prevalence and risk factors of video game dependency in adolescence: Results of a German nationwide survey. Cyberpsychology, Behavior, and Social Networking, 13(3), 269-277. doi:10.1089/cyber.2009.0227

Salovey, P., Mayer, J., Goldman, S. L., Turvey, C., \& Palfai, T. P. (1995). Emotional attention, clarity and repair Exploring emotional intelligence using the Trait Meta-Mood Scale. In J. W. Pennebaker (Ed.), Emotion, disclosure, and health (pp. 125-154). Washington, DC: American Psychiatric Association.

Schneider, L. A., King, D. L., \& Delfabbro, P. H. (2017). Maladaptive coping styles in adolescents with Internet gaming disorder symptoms. International Journal of Mental Health and Addiction, 16(4), 905-916. doi:10.1007/s11469-017-9756-9

Schulz, K. F., Altman, D. G., \& Moher, D. (2010). CONSORT 2010 statement: Updated guidelines for reporting parallel group randomized trials. Annals of Internal Medicine, 152(11), 726-732. doi:10.7326/0003-4819-152-11-201006 010-00232

Shapira, N. A., Goldsmith, T. D., Keck, P. E., Jr., Khosla, U. M., \& McElroy, S. L. (2000). Psychiatric features of individuals with problematic Internet use. Journal of Affective Disorders, 57(1-3), 267-272. doi:10.1016/S0165-0327(99)00107-X

Tejeiro, R. A., Gómez-Vallecillo, J. L., Pelegrina, M., Wallace, A., \& Emberley, E. (2012). Risk factors associated with the abuse of video games in adolescents. Scientific Research, 3(4), 310-314. doi:10.4236/psych.2012.34044

Therien, P., Lavarenne, S. A., \& Lecomte, T. (2014). The treatment of complex dual disorders: Clinicians' and service users' perspectives. Journal of Addiction Research and Therapy, 10(6), 2-7. doi:10.4172/2155-6105.S10-006

Thorens, G., Achab, S., Billieux, J., Khazaal, Y., Khan, R., Pivin, E., Gupta, V., \& Zullino, D. (2014). Characteristics and treatment response of self-identified problematic Internet users in a behavioral addiction outpatient clinic. Journal of Behavioral Addictions, 3(1), 78-81. doi:10.1556/JBA.3.2014.008

Torres-Rodríguez, A., \& Carbonell, X. (2015). Adicción a los videojuegos en línea: Tratamiento mediante el programa PIPATIC [Online video game addiction: Treatment through the PIPATIC program]. Aloma, 33(2), 67-75.

Torres-Rodríguez, A., \& Carbonell, X. (2017). Update and proposal of treatment for Internet gaming disorder: PIPATIC program. Revista de Psicoterapia, 28(107), 317-336.

Torres-Rodríguez, A., Griffiths, M. D., \& Carbonell, X. (2017). The treatment of Internet gaming disorder: A brief overview of the PIPATIC program. International Journal of Mental Health and Addiction, 16(4), 1000-1015. doi:10.1007/s11469-0179825-0

Torres-Rodríguez, A., Griffiths, M. D., Carbonell, X., \& Oberst, U. (2018). Internet gaming disorder in adolescence: Psychological characteristics of a clinical sample. Journal of Behavioral Addictions, 7(3), 707-718. doi:10.1556/2006.7. 2018.75 
Winkler, A., Dörsing, B., Rief, W., Shen, Y., \& Glombiewski, J. A. (2013). Treatment of Internet addiction: A meta-analysis. Clinical Psychology Review, 33(2), 317-329. doi:10.1016/j. cpr.2012.12.005

Wölfling, K., Beutel, M. E., Dreier, M., \& Muller, K. W. (2014). Treatment outcomes in patients with Internet addiction: A clinical pilot study on the effects of a cognitive-behavioral therapy program. BioMed Research International, 2014, 425924. doi: $10.1155 / 2014 / 425924$

World Health Organization. (2016). Gaming disorder. ICD-11 beta draft. Retrieved January 7, 2018, from https://icd. who.int/dev11/1-m/en\#/http\%3A\%2F\%2Fid.who.int\%2Ficd $\% 2$ Fentity\%2F1448597234

Yan, W., Li, Y., \& Sui, N. (2014). The relationship between recent stressful life events, personality traits, perceived family functioning and Internet addiction among college students. Stress and Health, 30(1), 3-11. doi:10.1002/smi.2490

Yao, Y. W., Chen, P. R., Li, C.-s. R., Hare, T. A., Li, S., Zhang, J. T., Liu, L., Ma, S.-S., \& Fang, X. Y. (2017). Combined reality therapy and mindfulness meditation decrease intertemporal decisional impulsivity in young adults with Internet gaming disorder. Computers in Human Behavior, 68, 210-216. doi:10.1016/j.chb.2016.11.038

Young, K. (2009). Understanding online gaming addiction treatment issues for adolescents. American Journal of Family Therapy, 37(5), 355-372. doi:10.1080/01926180902942191

Young, K. S. (2007). Cognitive behavior therapy with Internet addicts: Treatment outcomes and implications. CyberPsychology \& Behavior, 10(5), 671-679. doi:10.1089/cpb. 2007.9971

Young, K. S. (2013). Treatment outcomes using CBT-IA with Internet-addicted patients. Journal of Behavioral Addictions, 2(4), 209-215. doi:10.1556/JBA.2.2013.4.3

Zhang, J.-T., Yao, Y.-W., Potenza, M. N., Xia, C.-C., Lan, J., Liu, L., Wang, L. J., Liu, B., Ma, S. S., \& Fang, X.-Y. (2016). Altered resting-state neural activity and changes following a craving behavioral intervention for Internet gaming disorder. Scientific Reports, 6(1), 28109. doi:10.1038/srep28109 